\title{
Oxidative stability of camelina (Camelina sativa L.) oil using pressure differential scanning calorimetry and Rancimat method
}

\author{
Katarzyna Ratusz ${ }^{1}$ Edyta Popis ${ }^{1}$ Hanna Ciemniewska-Żytkiewicz ${ }^{2}$. \\ Małgorzata Wroniak ${ }^{1}$
}

Received: 14 November 2015 / Accepted: 16 June 2016/Published online: 1 July 2016

(C) The Author(s) 2016. This article is published with open access at Springerlink.com

\begin{abstract}
The camelina oil, registered in EU as Traditional Speciality Guaranteed, is an excellent edible oil rich in $\omega 3$ fatty acids, as well as a great raw material for biodiesel production. However, both variable seed quality and technological difficulties (cold pressing, no chemical refining procedure) exert an unfavorable impact on a final oil quality and its oxidative stability. Therefore, oxidative stability parameter seems to be a significant distinguishing feature of camelina oil. The aim of this work was to compare the oxidative stability of selected camelina oils and assessment of kinetic parameters of their oxidation determined by PDSC and the Rancimat methods. Coldpressed camelina oils were initially characterized by basic quality parameters: fatty acids composition, free fatty acids, peroxide value and anisidine value. The isothermal PDSC and Rancimat procedures were conducted within the temperature range of $90-130$ and $80-120^{\circ} \mathrm{C}$, respectively. From the obtained results, the times to reach the oxidation peak maximum $\left(\tau_{\max }\right)$ obtained from PDSC analysis were compared with induction times $\left(\tau_{\mathrm{on}}\right)$ determined by Rancimat test. Based on the Arrhenius equation and transition state theory, activation energies $\left(E_{\mathrm{a}}\right)$, pre-exponential factors $(Z)$ and specific rate constants $(k)$ of oils oxidation at selected temperatures were calculated. Strong correlation between PDSC and Rancimat methods $\left(R^{2}>0.98\right)$
\end{abstract}

Katarzyna Ratusz

katarzyna_ratusz@sggw.pl

1 Department of Food Technology, Faculty of Food Sciences, Warsaw University of Life Sciences, Nowoursynowska St. 166, 02-787 Warsaw, Poland

2 Department of Chemistry, Faculty of Food Sciences, Warsaw University of Life Sciences, Nowoursynowska St. 166, 02-787 Warsaw, Poland using a polynomial equation was obtained; thus, PDSC method can be preliminary recommended as an appropriate objective method for assessing the oxidative stability of camelina oils. To the best of our knowledge, this is the first study on the possible use of PDSC technique to analyze the kinetics of oxidation of camelina oil.

Keywords Camelina oil $\cdot$ Kinetic of oxidation $\cdot$ Oxidative stability $\cdot$ PDSC $\cdot$ Rancimat

\section{Introduction}

Camelina (Camelina sativa L.) Grantz, named camelina, German sesame, false flax, gold-of-pleasure, Siberian oilseed, linseed dodder or wild flax, is an oil plant belonging to the cabbage family (Brassicaceae). It is an annual plant, available in spring and winter varieties. Externally, it looks similar to the most important Polish oil plant-the rapeseed; it has similar, tiny yellow flowers, but its seeds are much smaller. It is indigenous to the entire Central European Plain; however, it is not common. Due to its low soil requirements and high resistance to low temperatures and periodic water deficits, it can be an attractive plant for sustainable agriculture. It was cultivated as early as 2000 years ago in Poland and in Scandinavia. Since the end of World War II, its large-scale cultivation was suspended; however, nowadays, interest in it has been growing rapidly [1-4].

Camelina seeds contain approximately 35-45\% oil, whereas the winter variety contains more oil than the spring one [1-5]. Camelina oil is obtained mainly through cold pressing, which, according to Codex Alimentarius [6], means oils obtained by mechanical procedures, without the application of heat or chemicals. Such oils are not chemically 
refined, and they may only be purified by washing with water, centrifuging, filtering or settling $[3,6,7]$.

Camelina oil is of high nutrition value due to content of polyunsaturated fatty acids (40-60\%), most of which belongs to the $n-3$ family: $\alpha$-linolenic acid (ALA) accounted for $35-40 \%$ [1, 3, 8-11]. Therefore, it lowers the LDL cholesterol levels in blood plasma. This oil also contains a large amount (15-18\%) of linoleic acid (LA) and over $30 \%$ of monounsaturated fatty acids, mainly oleic (C18:1) and eicosenoic (gadoleic) acids (C20:1) $[1,3,8-11]$. Saturated fatty acids, mainly stearic and palmitic acids, comprise only $7-9 \%$ of all fatty acids, and as a result, it is in agreement with nutritional recommendations $[8,9]$. Moreover, camelina oil is known to have a high concentration of tocopherols $\left(751-821 \mathrm{mg} \mathrm{kg}^{-1}\right)[11,12]$.

Such a high nutrition value of cold-pressed camelina oil results in its many applications, not only as a ready-to-eat food product—edible oil for direct consumption-but also as an ingredient in margarines, fat blends, sauces and dressings [2, 9, 11]. Cold-pressed camelina oil has been entered into the EU register of Traditional Specialities Guaranteed in 2009 (Regulation (EC) No. 506/2009 of 15 June 2009). Camelina oil is also used in cosmetic and pharmaceutical industries, among others, to manufacture creams and lotions. It is also used in the chemical industry; since now, there were few studies on the use of camelina oil for biodiesel production [9, 11, 13-15].

Oxidation stability is one of the most important parameters of edible oils, including camelina oil, describing their quality and suitability for processing. Many methods for its assessment are used in food chemistry. Chemical measurements, like titration analysis, are used less frequently in laboratory and industrial practice, which is strictly related to the development of various instrumental techniques. Accelerated oxidation tests using, for example, passing air through oil in elevated temperature are also commonly used. Metrohm Rancimat (Europe) test and OSI—oxidative stability index (USA)—are commonly applied for analysis of edible oils $[16,17]$, however, they cannot always be successfully used to analyze cold-pressed oils, despite being useful in assessing refined oils. Studies on oil oxidation using the DSC technique, under both isothermal (constant operating temperature) and dynamic conditions (linear temperature growth), have been carried out so far [17-20]. Nevertheless, studies were mostly conducted on refined oils [17, 20, 21]. Parameters of coldpressed oils-relatively high non-glycerol content, very high influence of the raw material on final product quality and pressing parameters on the oil content-make the selection of the appropriate method and conditions of the analysis arduous and difficult. There have been very little studies on kinetic analysis of oxidation of cold-pressed oils in general. As far as we know, there are no studies on parameters of oxidation kinetics for cold-pressed camelina oil.

The aim of this study was to compare the oxidative stability of selected camelina oils and assessment of kinetic parameters of their oxidation determined by the PDSC and Rancimat methods.

\section{Materials and methods}

\section{Chemicals}

All the solvents (chloroform, diethyl ether, ethanol, methanol and n-hexane) and reagents (acetic acid, potassium iodide, potassium hydroxide, sodium thiosulfate, starch soluble and phenolphthalein) used were of analytical grade and are purchased from P.O.Ch Co. (Gliwice, Poland).

\section{Materials}

Camelina sativa seeds (samples 1-4) were obtained from four different cultivation areas in Wielkopolska, Poland. The seeds were cold-pressed using a Farmet press at the oil press in Starachowice, Poland. Pressed oils were subjected to $24 \mathrm{~h}$ of decantation and then filtered. The procedure was carried out according to a standard procedure developed by Farmet plant for preparing cold-pressed oils. The remaining two oil samples (5 and 6) were purchased on local market as food-grade commercial products.

\section{Chemical analyses}

Peroxide values (PV) of oils were determined by iodometric technique and free fatty acid (\%FFA) was determined by titration with $0.1 \mathrm{M}$ ethanolic potassium hydroxide, while anisidine value $(\mathrm{AnV})$ was determined spectrophotometrically in accordance with Standards ISO 3960:2012, ISO 660:2009 and ISO 6885:2012 [22-24], respectively. Spectrophotometric AnV measurements were conducted in quartz cuvettes with the $10 \mathrm{~mm}$ optical path length on a Helios Gamma UV-Vis Spectrophotometer.

\section{Fatty acid analysis}

The fatty acid composition of oil samples presented in Table 1 was determined according to the AOCS Official Method Ce 1h-05 with minor modifications [25]. Preparation of fatty acid methyl esters was conducted according to the AOCS Official Method Ce 2-66 [26]. Analysis was carried out using a Hewlett-Packard model 5890 II gas chromatograph (Agilent Technologies, Avondale, PA, USA) with a flame ionization detector equipped with a Supelcowax 10 column $(30 \mathrm{~m} \times 0.25 \mathrm{~mm} \times 0.25 \mu \mathrm{m})$. 
Table 1 Parameters of camelina oil samples

\begin{tabular}{|c|c|c|c|c|c|c|}
\hline \multirow[t]{2}{*}{ Parameter } & \multicolumn{6}{|l|}{ Camelina oil } \\
\hline & $\mathrm{CO} 1$ & $\mathrm{CO} 2$ & $\mathrm{CO} 3$ & $\mathrm{CO} 4$ & $\mathrm{CO} 5$ & $\mathrm{CO} 6$ \\
\hline Free fatty acids (FFA\%) & $0.32 \pm 0.03^{\mathrm{ab}}$ & $0.48 \pm 0.05^{\mathrm{b}}$ & $0.14 \pm 0.02^{\mathrm{a}}$ & $0.19 \pm 0.06^{\mathrm{ab}}$ & $0.23 \pm 0.04^{\mathrm{ab}}$ & $0.86 \pm 0.11^{\mathrm{c}}$ \\
\hline Peroxide value (meq $\mathrm{O}_{2} \mathrm{~kg}^{-1}$ ) & $2.04 \pm 0.09^{\mathrm{ab}}$ & $1.24 \pm 0.13^{\mathrm{abc}}$ & $1.62 \pm 0.05^{\mathrm{cd}}$ & $1.41 \pm 0.08^{\mathrm{bc}}$ & $0.94 \pm 0.05^{\mathrm{ab}}$ & $0.79 \pm 0.09^{\mathrm{a}}$ \\
\hline Anisidine value (absorption $\times 100$ ) & $0.41 \pm 0.04^{\mathrm{ab}}$ & $0.56 \pm 0.04^{\mathrm{bc}}$ & $0.29 \pm 0.03^{\mathrm{a}}$ & $0.78 \pm 0.05^{\mathrm{c}}$ & $0.36 \pm 0.08^{\mathrm{ab}}$ & $0.38 \pm 0.02^{\mathrm{ab}}$ \\
\hline \multicolumn{7}{|l|}{ Main fatty acids (\%) } \\
\hline C16:0 & $6.17 \pm 0.03$ & $4.69 \pm 0.05$ & $4.87 \pm 0.01$ & $5.92 \pm 0.11$ & $6.11 \pm 0.08$ & $6.16 \pm 0.02$ \\
\hline C18:0 & $2.43 \pm 0.05$ & $1.63 \pm 0.02$ & $1.78 \pm 0.06$ & $2.86 \pm 0.03$ & $2.49 \pm 0.03$ & $2.47 \pm 0.05$ \\
\hline C18:1 & $16.47 \pm 0.11$ & $15.39 \pm 0.08$ & $16.25 \pm 0.12$ & $14.78 \pm 0.11$ & $16.57 \pm 0.08$ & $14,56 \pm 0.07$ \\
\hline C18:2 & $18.58 \pm 0.08$ & $18.65 \pm 0.11$ & $18.02 \pm 0.05$ & $18.36 \pm 0.14$ & $18.71 \pm 0.06$ & $18.91 \pm 0.11$ \\
\hline C18:3 & $36.22 \pm 0.11$ & $37.64 \pm 0.12$ & $37.08 \pm 0.09$ & $35.35 \pm 0.11$ & $36.12 \pm 0.05$ & $36.85 \pm 0.07$ \\
\hline C20:0 & $1.16 \pm 0.05$ & $1.33 \pm 0.03$ & $1.26 \pm 0.02$ & $1.16 \pm 0.07$ & $1.16 \pm 0.05$ & $1.53 \pm 0.03$ \\
\hline C20:1 & $13.73 \pm 0.09$ & $15.53 \pm 0.04$ & $15.99 \pm 0.11$ & $13.93 \pm 0.03$ & $13.60 \pm 0.08$ & $15.01 \pm 0.11$ \\
\hline C20:2 & $1.78 \pm 0.05$ & $1.87 \pm 0.08$ & $1.62 \pm 0.02$ & $1.81 \pm 0.05$ & $1.71 \pm 0.11$ & $1.66 \pm 0.05$ \\
\hline C20:4 & $1.32 \pm 0.03$ & $0.31 \pm 0.02$ & $0.20 \pm 0.03$ & $1.31 \pm 0.01$ & $1.31 \pm 0.02$ & $0.42 \pm 0.01$ \\
\hline $\mathrm{C} 22: 1$ & $1.93 \pm 0.05$ & $0.78 \pm 0.04$ & $1.03 \pm 0.03$ & $2.01 \pm 0.11$ & $1.79 \pm 0.05$ & $1.88 \pm 0.08$ \\
\hline Others* & 0.21 & 2.18 & 1.9 & 2.51 & 0.43 & 0.46 \\
\hline$\Sigma \mathrm{SFA}^{*}$ & 9.76 & 7.65 & 7.91 & 9.94 & 9.76 & 9,24 \\
\hline$\Sigma$ MUFA* & 32.13 & 31.7 & 33.27 & 30.72 & 31.96 & 32.16 \\
\hline$\Sigma$ PUFA* & 57.9 & 58.47 & 56.92 & 56.83 & 57.85 & 58.14 \\
\hline
\end{tabular}

Data expressed as mean \pm standard deviation $(n=3)$

Means within the same row followed by different letters were significantly different at $P<0.05$

SFA saturated fatty acids, PUFA polyunsaturated fatty acids, MUFA monounsaturated fatty acids, *calculated values

The injector temperature was set to $240{ }^{\circ} \mathrm{C}$ with the split mode (1:25). The operating conditions were as follows: hydrogen flow $1 \mathrm{~mL} \min ^{-1}$ and oven temperature $220{ }^{\circ} \mathrm{C}$. Detector temperature was set at $240{ }^{\circ} \mathrm{C}$. Peaks were identified by comparing retention times with the FAME reference standard.

\section{Oxidative stability by pressure differential scanning calorimetry (PDSC)—isothermal measurements}

The oxidative stability of tested oils was determined using differential scanning calorimeter (DSC Q20P, TA Instruments, USA) coupled with a high-pressure cell (series DSC Pressure Cell, TA Instruments). The equipment was calibrated using high-purity indium and tin metal standards. Oil samples of 3-4 mg were weighted into an aluminum open pans and placed in the sample chamber under oxygen atmosphere with initial pressure of $1400 \mathrm{kPa}$ (filling the chamber with the $100 \mathrm{~mL} \mathrm{~min}^{-1}$ oxygen flow rate). The isothermal temperature for each sample was programmed at five selected temperatures in the range of $90-130{ }^{\circ} \mathrm{C}$. Obtained diagrams were analyzed using TA Universal Analysis 2000 software. For each sample, the output was automatically recalculated and presented as amount of energy per $1 \mathrm{~g}$. The maximum PDSC oxidation rate time $\left(\tau_{\max }\right)$ was determined based on the maximum rate of oxidation (maximum rate of heat flow) with the accuracy of 0.005 .

\section{Oxidative stability by Rancimat measurements}

The oxidative stability was determined with 743 Rancimat apparatus from Metrohm, Herisau, Switzerland, according to ISO 6886:2009 [27], utilizing a sample of $2.50 \mathrm{~g} \pm 0.01 \mathrm{~g}$. All samples were studied in five temperatures $\left(80,90,100,110\right.$ and $\left.120^{\circ} \mathrm{C}\right)$, under a constant air flow $\left(20 \mathrm{~L} \mathrm{~h}^{-1}\right)$. The induction times were printed automatically by the apparatus software with the accuracy of 0.005 .

\section{Statistical analysis}

Relative standard deviation was obtained, where appropriate, for all collected data. All chemical analyses were carried out in triplicate $(n=3)$ for each sample. In case of oxidation stability determination, for each camelina oil at each temperature, three experiments were performed and the average Rancimat $\tau_{\text {on }}$ and PDSC $\tau_{\max }$ values were 
calculated. Relationships between pairs of variables were evaluated using regression analysis, linear and polynomial. Coefficients of determination $R^{2}$ which indicate how well data fit a regression model were presented [28]. Possible range of $R^{2}$ is from 0 to 1 , and the higher value indicates that the regression function better describes the examined relationship.

One-way analysis of variance, ANOVA (Tukey's honest significant difference multiple comparison), was evaluated using Statistica 10.0 software (2010, StatSoft, Tulsa, OK, USA). $P$ values lower than 0.05 were considered statistically significant.

\section{Results and discussion}

Despite a relatively high variation of free fatty acid content (\%FFA), peroxide (PV) and anisidine values (AnV) presented in Table 1, values remained low, which reflects a very high quality of tested oils. The FFA content $(0.14-0.86 \%)$ and PV (0.79-2.04 meq $\left.\mathrm{O}_{2} \mathrm{~kg}^{-1}\right)$ in tested camelina oils were similar to results presented by Raczyk et al. [9] and Abramovic et al. [12]. The obtained results indicate that tested camelina oils meet the requirements for edible oils specified by Codex Alimentarius (\% FFA $<4 \%$, PV $<15$ meq $\mathrm{O}_{2} \mathrm{~kg}^{-1}$ ) [6]. Neither Codex Alimentarius nor ISO procedure does not describe the AnV limits for cold-pressed oils. However, to do more complex characterization of camelina oils taken into analysis, AnV was examined. AnV, indicating the secondary oxidation products' content, was low (0.29-0.78), as well. It is typical for fresh cold-pressed oils, due to no heat treatment applied during fat extraction, which would strengthen oxidation process. Similar results were obtained by Raczyk et al. [9] in camelina oils (0.46-1.60) and Wroniak et al. [7] in coldpressed rapeseed oils (0.64-0.81).

Fatty acid profile of studied camelina oils presented in Table 1 indicates a very low saturated fatty acid content (SFA) (7.65-9.94\%). Similar results were obtained by Minkowski et al. [8], who identified a 8.7 \% SFA content, by Raczyk et al. [9] (9.6-10.6 \%) and by Zubr and Matthaus [29] (9.8\%). Next to oleic acid (C18:1) content (14.56-16.57\%), high eicosanoic acid (C20:1) content is a characteristic for camelina oil (13.6-15.99\%). It was previously confirmed by Raczyk et al. [9] and Szterk et al. [10]. Camelina oil studied by Minkowski et al. [30] contained even more eicosanoic acid-20.7\%. Camelina oil is also known as an abundant source of PUFA [1, 3, 8-11]. Herein, oils tested contained 56.83-58.47\% PUFA of all fatty acids. Conducted analysis indicated that the undeniably valuable $\mathrm{C} 18: 3$ acid comprises $35.35-37.6 \%$ of all fatty acids in studied camelina oils. Oils studied by Hrastar et al. [3], Raczyk et al. [9] and Minkowski et al. [30] contained similar quantities (33.32-37.65\%). Such a high level of $\alpha$ linolenic acid makes camelina oil an excellent source of n-3 acids in human diet. The linoleic acid content (C18:2) was also significant (18.02-18.91\%). These results were confirmed by many studies $[1,3,8,11,12]$.

Results of induction time analysis performed using Rancimat and PDSC methods are presented in Table 2. High variability of results depends on the matrix tested. Cold-pressed oils, including camelina oil, are unique and complex materials. However, their oxidative stability is not only dependent on initial raw material chemical composition. Following factors are significant as well: degree of seeds maturity, mechanical damages, moisture, contaminations; seeds' processing conditions, like preliminary humidifying, seeds' heating and cold-pressing conditionspress pressure, temperature of pressed oil, time and temperature of sedimentation and filtration [7, 9, 31]. As presented in Materials and methods section, four oils (1-4) were pressed in the same processor; however, raw material (seeds) was cultivated in different locations. Two oils $(5,6)$ were purchased in a local market. Different origin of raw material and further processing had an impact on high dispersion of oxidative stability results obtained herein. From the methodology point of view, high variability of results was expected. As far as authors know, wide quality range of oils tested and strong correlations obtained are enough to conclude about camelina oil in general.

The differentiation of samples tested using PDSC performed at $120{ }^{\circ} \mathrm{C}$ for the samples of camelina oils (1-6) is presented in Fig. 1.

Results obtained with Rancimat and PDSC methods describe the oxidative stability, but these results do not correspond to the same oxidation stages. However, along with the increase in measurement temperature, both $\tau_{\max }$ and $\tau_{\text {on }}$ obtained using both methods were getting lower. Kowalski et al. [17] presented convergent relationship in studies on refined oils: rapeseed, soy and sunflower; Zaanoun et al. [32] studied argan oil as well. As far as authors know, no oxidation stability analysis was presented for camelina oils at various temperatures. Most researches assessed the oxidative stability of this oil using only the Rancimat test at $100{ }^{\circ} \mathrm{C}[9,10]$. Induction time value $\left(\tau_{\text {on }}\right)$ for camelina oils quantified using the Rancimat test, herein, was from 4.58 to $5.63 \mathrm{~h}$. Similar results were obtained by Raczyk et al. [9] (4.58-6.16 h) and by Szterk et al. [10] (6.12 h). Abramowič and Abram [33] presented oxidation stability of camelina oil at $110{ }^{\circ} \mathrm{C}$ and obtained a higher value $(4.8 \mathrm{~h})$ than presented herein $(2.44-3.10 \mathrm{~h})$. Increased oxidation stability could be explained by lower content of PUFA (55.8\%) in Abramowič and Abram [33] study, since the autooxidation rates of fatty acids relate significantly to degree of their unsaturation. Rancimat analysis performed at $120{ }^{\circ} \mathrm{C}$ demonstrated very low values of $\tau_{\text {on }}(<1 \mathrm{~h})$. 
Table 2 Rancimat and PDSC induction time for camelina oils

\begin{tabular}{|c|c|c|c|c|c|c|}
\hline \multirow[t]{2}{*}{ Temperature $/{ }^{\circ} \mathrm{C}$} & \multicolumn{6}{|l|}{ Induction time } \\
\hline & $\mathrm{CO} 1$ & $\mathrm{CO} 2$ & $\mathrm{CO} 3$ & $\mathrm{CO} 4$ & $\mathrm{CO} 5$ & CO6 \\
\hline \multicolumn{7}{|l|}{ Rancimat $\tau_{\text {on }} / \mathrm{h}$} \\
\hline 120 & $0.45 \pm 0.11^{\mathrm{a}}$ & $0.63 \pm 0.12^{\mathrm{a}}$ & $0.55 \pm 0.14^{\mathrm{a}}$ & $0.45 \pm 0.14^{\mathrm{a}}$ & $0.62 \pm 0.15^{\mathrm{a}}$ & $0.70 \pm 0.16^{\mathrm{a}}$ \\
\hline 110 & $2.84 \pm 0.07^{\mathrm{ab}}$ & $3.10 \pm 0.05^{\mathrm{b}}$ & $2.87 \pm 0.05^{\mathrm{ab}}$ & $2.44 \pm 0.06^{\mathrm{c}}$ & $2.94 \pm 0.07^{\mathrm{ab}}$ & $2.57 \pm 0.09^{\mathrm{ac}}$ \\
\hline 100 & $5.21 \pm 0.11^{\mathrm{a}}$ & $5.63 \pm 0.10^{\mathrm{a}}$ & $5.56 \pm 0.13^{\mathrm{a}}$ & $4.58 \pm 0.08^{\mathrm{b}}$ & $5.12 \pm 0.11^{\mathrm{ab}}$ & $5.19 \pm 0.12^{\mathrm{ab}}$ \\
\hline 90 & $9.91 \pm 0.15^{\mathrm{ab}}$ & $9.57 \pm 0.16^{\mathrm{a}}$ & $11.14 \pm 0.12^{\mathrm{c}}$ & $10.12 \pm 0.11^{\mathrm{ab}}$ & $13.00 \pm 0.18^{\mathrm{d}}$ & $10.50 \pm 0.20^{\mathrm{bc}}$ \\
\hline 80 & $22.97 \pm 0.34^{\mathrm{a}}$ & $23.18 \pm 0.42^{\mathrm{a}}$ & $23.21 \pm 0.35^{\mathrm{a}}$ & $23.50 \pm 0.27^{\mathrm{ab}}$ & $25.30 \pm 0.28^{\mathrm{b}}$ & $22.55 \pm 0.26^{\mathrm{a}}$ \\
\hline \multicolumn{7}{|l|}{$\operatorname{PDSC} \tau_{\max } / \min$} \\
\hline 130 & $15.39 \pm 0.21^{\mathrm{ab}}$ & $15.60 \pm 0.32^{\mathrm{ab}}$ & $15.92 \pm 0.43^{\mathrm{ab}}$ & $14.08 \pm 0.87^{\mathrm{a}}$ & $16.83 \pm 0.54^{\mathrm{b}}$ & $16.03 \pm 0.43^{\mathrm{ab}}$ \\
\hline 120 & $26.81 \pm 1.11^{\mathrm{b}}$ & $33.67 \pm 0.89^{\mathrm{a}}$ & $35.45 \pm 1.08^{\mathrm{a}}$ & $28.31 \pm 1.04^{\mathrm{b}}$ & $37.31 \pm 0.23^{\mathrm{a}}$ & $35.85 \pm 0.67^{\mathrm{a}}$ \\
\hline 110 & $67.02 \pm 0.53^{\mathrm{a}}$ & $68.50 \pm 0.96^{\mathrm{a}}$ & $73.00 \pm 0.76^{\mathrm{c}}$ & $61.17 \pm 0.54^{\mathrm{b}}$ & $78.91 \pm 0.72^{\mathrm{d}}$ & $67.59 \pm 0.83^{\mathrm{a}}$ \\
\hline 100 & $154.75 \pm 1.34^{\mathrm{ab}}$ & $156.66 \pm 0.47^{\mathrm{ab}}$ & $158.29 \pm 1.23^{\mathrm{ab}}$ & $151.91 \pm 0.34^{\mathrm{a}}$ & $172.25 \pm 1.56^{\mathrm{c}}$ & $159.62 \pm 1.41^{\mathrm{b}}$ \\
\hline 90 & $317.13 \pm 1.54^{\mathrm{b}}$ & $329.09 \pm 1.09^{\mathrm{a}}$ & $332.56 \pm 1.43^{\mathrm{a}}$ & $345.45 \pm 0.67^{\mathrm{c}}$ & $394.67 \pm 1.05^{\mathrm{e}}$ & $357.45 \pm 2.04^{\mathrm{d}}$ \\
\hline
\end{tabular}

Means within the same row followed by different letters were significantly different at $P<0.05$

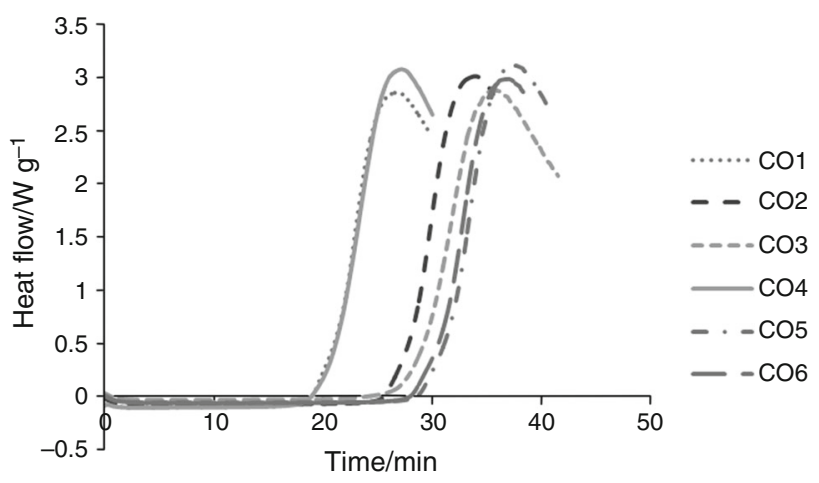

Fig. 1 PDSC curves obtained at $120{ }^{\circ} \mathrm{C}$ for the different samples of camelina oils

According to Ratusz et al. [34] and Kowalski et al. [17], oils rich in polyenoic acids, such as camelina oil, display convergent characteristics in higher operating temperatures set in Rancimat test.

In up-to-date literature, there is only one study [9] on oxidation stability for camelina oils using differential scanning calorimetry, where thermoanalytical analysis was conducted only for selected temperatures. Raczyk et al. [9] studied the oil at $120^{\circ} \mathrm{C}$ and obtained $\tau_{\max }$ between 27.9 and $32.3 \mathrm{~min}$. Herein, similar results of $\tau_{\max }$ at $120^{\circ} \mathrm{C}-$ from 26.81 to $37.31 \mathrm{~min}$-were obtained (Table 2).

Several researchers $[17,18,30-32,35]$ compared results of oxidation stability obtained using DSC and traditional oxidative tests, such as Rancimat. However, no research concerning the application of PDSC technique and Rancimat test in the analysis of camelina oil oxidation kinetics was found. $\tau_{\text {on }}$ values from Rancimat tests presented in
Table 2 were higher from $\tau_{\max }$ values obtained using the PDSC method for all temperatures tested. The reason for this may be the size of tested samples (3-4 mg for PDSC in comparison with $2.5 \mathrm{~g}$ for Rancimat tests), which is emphasized by Tan et al. [18]. It could be also explained by the fact that oil in Rancimat tests is oxidized using air containing approx. $21 \%$ of oxygen with a flow of $20 \mathrm{l} \mathrm{h}^{-1}$, whereas in PDSC, it is oxidized using pure oxygen in highpressure conditions (approx. $1400 \mathrm{kPa}$ ) [35]. Additionally, the PDSC method measures the differences of heat flow between oil tested and reference sample (empty vessel). The highest differences $\left(\tau_{\max }\right)$ are correlated with rapid increase in peroxides concentration (propagation of autooxidation). However, the Rancimat method evaluates later oxidation stage, the time $\left(\tau_{\mathrm{on}}\right)$ that elapses until secondary (volatile) reaction products appear $[17,18]$.

To evaluate relationships between results obtained using both methods, induction times obtained using Rancimat tests $\left(\tau_{\text {on }}\right)$ and PDSC $\left(\tau_{\max }\right)$ were compared for four measurement temperatures $\left(90,100,110\right.$ and $\left.120{ }^{\circ} \mathrm{C}\right)$. Obtained relationships are shown in Fig. 2 as a result of polynomial regression analysis. The conducted analysis indicated a strong relationship between results using both methods. Dependencies shown in Fig. 2 for camelina oils between results of both analyzed analytical techniquesPDSC and Rancimat—can be described using a polynomial equation.

$$
\begin{aligned}
& \quad\left\{\text { PDSC } \tau_{\max }=-0.4112 \text { Rancimat } \tau_{\text {on }}^{3}\right. \\
& \left.\quad+7.6708 \text { Rancimat } \tau_{\text {on }}^{2}-5.1399 \text { Rancimat } \tau_{\text {on }}+33.885\right\}
\end{aligned}
$$

Coefficient of determination of presented correlation was $R^{2}=0.9858$. Therefore, it can be stated that for 


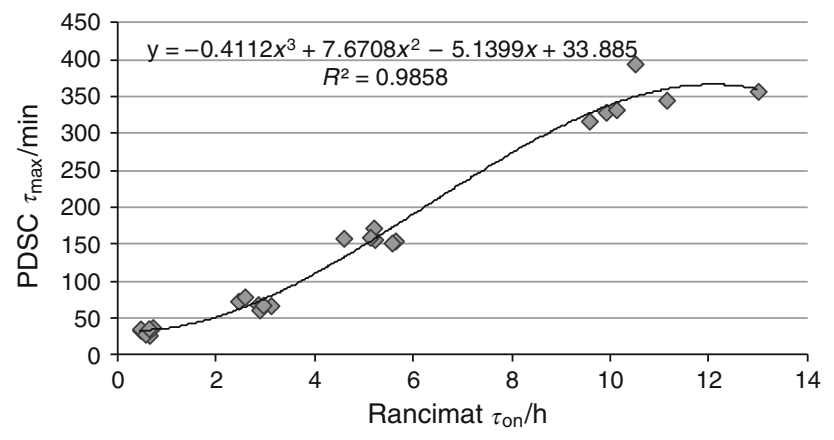

Fig. 2 Relationships between PDSC $\tau_{\max }$ and Rancimat $\tau_{\text {on }}$ induction time for camelina oil presented as results of polynomial regression (third-order function)

analysis conducted in temperatures between 90 and $120{ }^{\circ} \mathrm{C}$, both methods are substitutable.

\section{Kinetic analysis of Rancimat and PDSC data}

Determining parameters of oil oxidation kinetics allows us to better assess their oxidation stability, suitability for processing and resistance to high temperatures during processing and storage $[16,17,20,36]$.

Oxidation times determined for Rancimat $\left(\tau_{\text {on }}\right)$ and PDSC $\left(\tau_{\max }\right)$ techniques presented in Table 2 enabled to prepare the graphical dependences between logarithm of $\tau_{\max }$ and $\tau_{\text {on }}$ and temperature (Figs. 3, 4). Linear relationship presented in Figs. 3 and 4 can be described by the general regression equation:

$\log \tau_{\text {on }}$ or $\log \tau_{\max }=a T+b$

where $a$ and $b$ are adjustable coefficients and $T$ are the temperatures expressed in ${ }^{\circ} \mathrm{C}$.

Quantified regression coefficient values $a$, regression constant $b$ and the determination coefficients $R^{2}$ are

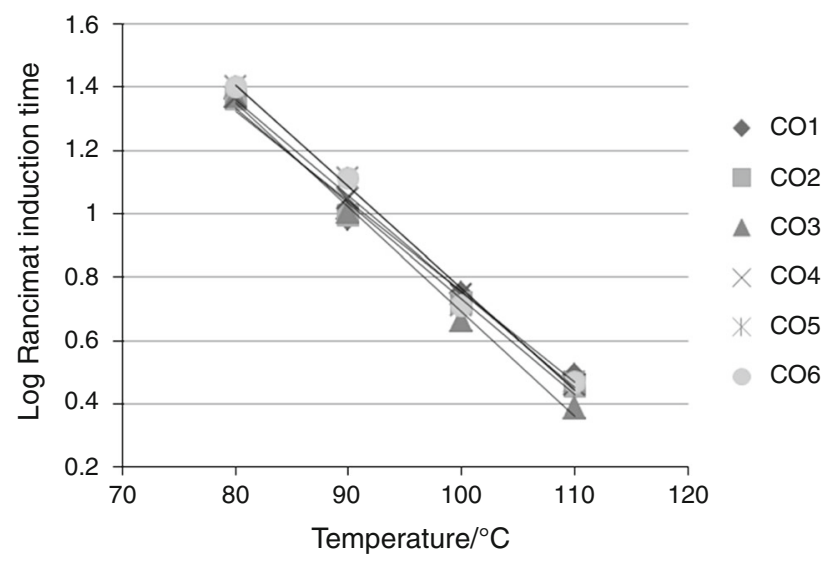

Fig. 3 Log Rancimat induction time $\left(\tau_{\text {on }}\right)$ versus temperature for oxidation of camelina oil

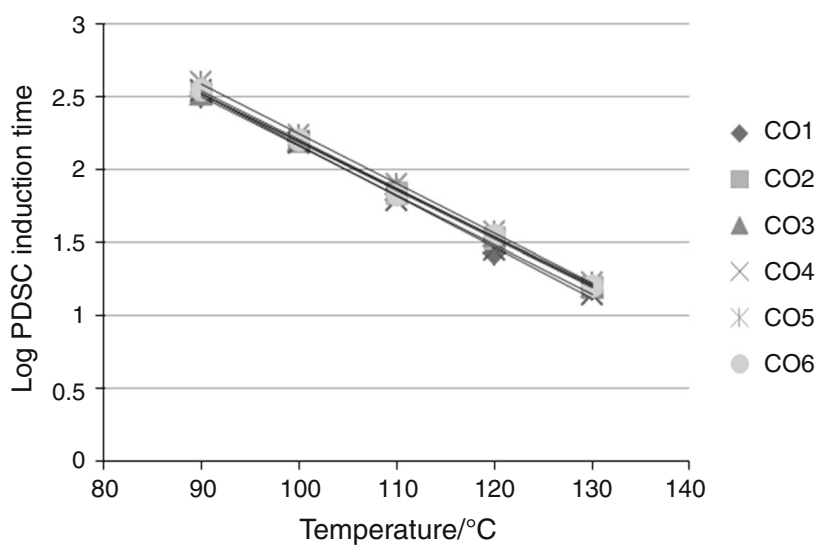

Fig. 4 Log PDSC induction time $\left(\tau_{\max }\right)$ versus temperature for oxidation of camelina oil

presented in Table 3. Regression lines presented in Figs. 3 and 4 are $99 \%$ identical with results obtained during experiments. Due to such a high goodness of fit, using these charts, it is possible to determine induction times for temperatures, in which research was not conducted [16-18].

Since oil oxidation in excess of oxygen (air) is an apparent first-order reaction, accordingly for any constant conversion of the oxidized oil, the kinetic analysis can be performed. Oxidation of vegetable oil studied using PDSC corresponds to the maximum heat flow difference noticeable on the PDSC diagrams, which is correlated with state of autooxidation propagation [17, 18, 36]. Calculating kinetic parameters of camelina oil oxidation based on Eq. 2 will facilitate results presented in Table 2. Correlation equation taking into account temperature expressed in $K$, which is a starting point for further calculations, was as follows [17, 18, 35, 37]:

$\log \tau_{\text {on }}$ or $\log \tau_{\max }=A T^{-1}+B$

where $A$ and $B$ are adjustable coefficients and $T$ are the temperatures expressed in $\mathrm{K}$.

Table 3 contains calculated values of regression coefficients $a$, $A$, regression constants $b, B$, determination coefficients $R^{2}$, activation energy $\left(E_{\mathrm{a}}\right)$, pre-exponential factor $(Z)$, oxidation rates $(k)$, activation enthalpies $\left(\Delta H^{\dagger}\right)$ and activation entropies $\left(\Delta S^{\ddagger}\right)$.

The activation energy values were calculated according to Ozawa-Flynn-Wall method adjusted for isothermal process:

$E_{\mathrm{a}}=2.19 \times R \times A$

where $R$ is the gas constant and $A$ is the slope of the $\log \tau_{\max / \text { on }}=f\left(T^{-1}\right)$ curve.

Based on these values (the determined regression line) from the reciprocal of temperature and the Arrhenius Eq. (4), pre-exponential factor $Z\left(h^{-1}\right)$ and the constant 
Table 3 Kinetic oxidation parameters of Camelina sativa oils based on Rancimat and PDSC results

\begin{tabular}{|c|c|c|c|c|c|c|}
\hline \multirow[t]{2}{*}{ Parameter } & \multicolumn{6}{|c|}{ Rancimat calculation based on $\tau_{\text {on }}$ measurement } \\
\hline & $\mathrm{CO} 1$ & $\mathrm{CO} 2$ & $\mathrm{CO} 3$ & $\mathrm{CO} 4$ & CO5 & CO6 \\
\hline \multicolumn{7}{|l|}{ Equation 1} \\
\hline$-\mathrm{a}$ & 0.0300 & 0.0285 & 0.0303 & 0.2950 & 0.0321 & 0.0321 \\
\hline B & 3.7345 & 3.6060 & 3.7780 & 3.6917 & 3.9722 & 3.9722 \\
\hline$R^{2}$ & 0.9938 & 0.9865 & 0.9995 & 0.9919 & 0.9914 & 0.9914 \\
\hline \multicolumn{7}{|l|}{ Equation 2} \\
\hline A & 4.0687 & 3.8662 & 4.0939 & 4.0009 & 4.3435 & 4.2429 \\
\hline$-\mathrm{B}$ & 10.1800 & 9.6143 & 10.2270 & 9.9904 & 10.8850 & 10.6610 \\
\hline$R^{2}$ & 0.9969 & 0.9907 & 0.9983 & 0.9952 & 0.9923 & 0.9999 \\
\hline$E_{\mathrm{a}} / \mathrm{kJ} \mathrm{mol}^{-1}$ & 74.08 & 70.39 & 74.54 & 72.85 & 79.08 & 77.25 \\
\hline$Z^{*}$ & $1.51 \times 10^{10}$ & $4.11 \times 10^{9}$ & $1.69 \times 10^{10}$ & $1.91 \times 10^{10}$ & $7.67 \times 10^{10}$ & $4.58 \times 10^{10}$ \\
\hline $\mathrm{k}^{*}$ at $110^{\circ} \mathrm{C}$ & 1.1998 & 1.0391 & 1.1627 & 1.5873 & 1.2670 & 1.3446 \\
\hline $\mathrm{k}^{*}$ at $100^{\circ} \mathrm{C}$ & 0.6434 & 0.5747 & 0.6211 & 0.8011 & 0.6514 & 0.7020 \\
\hline $\mathrm{k}^{*}$ at $90^{\circ} \mathrm{C}$ & 0.3333 & 0.3077 & 0.3205 & 0.3894 & 0.3228 & 0.3536 \\
\hline $\mathrm{k}^{*}$ at $80^{\circ} \mathrm{C}$ & 0.1664 & 0.1590 & 0.1593 & 0.1817 & 0.1538 & 0.1713 \\
\hline$\Delta H^{++} / \mathrm{kJ} \mathrm{mol}^{-1}$ & 71.02 & 67.33 & 72.29 & 78.21 & 72.27 & 72.26 \\
\hline$\Delta S^{++} / \mathrm{J} \mathrm{mol} \mathrm{K}{ }^{-1}$ & -60.12 & -70.95 & -56.92 & -39.02 & -56.97 & -56.73 \\
\hline \multirow[t]{2}{*}{ Parameter } & \multicolumn{6}{|c|}{ PDSC calculation based on $\tau_{\max }$ measurement } \\
\hline & $\mathrm{CO} 1$ & $\mathrm{CO} 2$ & $\mathrm{CO} 3$ & $\mathrm{CO} 4$ & $\mathrm{CO} 5$ & CO6 \\
\hline \multicolumn{7}{|l|}{ Equation 1} \\
\hline$-a$ & 0.0339 & 0.0332 & 0.0329 & 0.0351 & 0.034 & 0.0335 \\
\hline$B$ & 0.5548 & 5.5013 & 5.4859 & 5.6815 & 5.6506 & 5.5488 \\
\hline$R^{2}$ & 0.9951 & 0.9996 & 0.9998 & 0.9978 & 0.9997 & 0.9981 \\
\hline \multicolumn{7}{|l|}{ Equation 2} \\
\hline$A$ & 4.9632 & 4.8532 & 4.8126 & 5.1411 & 4.9835 & 4.8986 \\
\hline$-B$ & 11.145 & 10.83 & 10.71 & 11.615 & 11.119 & 10.933 \\
\hline$R^{2}$ & 0.9957 & 0.9991 & 0.9993 & 0.9993 & 0.9994 & 0.9987 \\
\hline$E_{\mathrm{a}} / \mathrm{kJ} \mathrm{mol}^{-1}$ & 90.37 & 88.37 & 87.63 & 93.61 & 90.74 & 89.19 \\
\hline$Z^{*}$ & $1.40 \times 10^{11}$ & $6.76 \times 10^{10}$ & $5.13 \times 10^{10}$ & $4.12 \times 10^{11}$ & $1.32 \times 10^{11}$ & $8.57 \times 10^{10}$ \\
\hline$k^{*}$ at $130{ }^{\circ} \mathrm{C}$ & 0.2734 & 0.2398 & 0.2269 & 0.3060 & 0.2308 & 0.2380 \\
\hline$k^{*}$ at $120^{\circ} \mathrm{C}$ & 0.1377 & 0.1226 & 0.1167 & 0.1504 & 0.1159 & 0.1210 \\
\hline$k^{*}$ at $110^{\circ} \mathrm{C}$ & 0.0669 & 0.0605 & 0.0580 & 0.0712 & 0.0562 & 0.0593 \\
\hline$k^{*}$ at $100{ }^{\circ} \mathrm{C}$ & 0.0313 & 0.0288 & 0.0277 & 0.0324 & 0.0262 & 0.0280 \\
\hline$k^{*}$ at $90{ }^{\circ} \mathrm{C}$ & 0.0140 & 0.0131 & 0.0127 & 0.0141 & 0.0117 & 0.0127 \\
\hline$\Delta H^{++} / \mathrm{kJ} \mathrm{mol}^{-1}$ & 87.18 & 85.18 & 84.44 & 90.42 & 87.55 & 86.00 \\
\hline$\Delta \mathrm{S}^{++} / \mathrm{J} \mathrm{mol} \mathrm{K}^{-1}$ & -41.94 & -48.00 & -50.29 & -32.97 & -42.43 & -46.03 \\
\hline
\end{tabular}

$* Z$ and $k$ from Rancimat in $\mathrm{h}^{-1}$ from PDSC in $\min ^{-1}$

oxidation rates $(k)$ for all measurement temperatures were calculated:

$k=Z \exp \frac{-E_{\mathrm{a}}}{R T}$

where $k$ is the specific rate constant and $R$ is the gas constant.
Based on the transition state theory, using Eq. (5) and the corresponding regression parameters, the activation enthalpies $\left(\Delta H^{\ddagger}\right)$ and activation entropies $\left(\Delta S^{\ddagger}\right)$ for oxidation of camelina oils were calculated:

$\ln \left(k T^{-1}\right)=\ln \left(k_{\mathrm{B}} h^{-1}\right)+\left(\Delta S^{\ddagger} R^{-1}\right)-\left(\Delta H^{\ddagger}(R T)^{-1}\right)$ 
where $k_{\mathrm{B}}$ is the Boltzmann constant and $h$ is the Planck's constant.

The $\Delta H^{\ddagger}$ and $\Delta S^{\ddagger}$ were calculated from the slopes and intercepts of the lines. The calculations were performed according to [17, 18, 35-37].

For camelina oils, it was observed that $E_{\mathrm{a}}$ varied in the range of $70.39-79.08$ and $87.63-93.61 \mathrm{~kJ} \mathrm{~mol}^{-1}$ for Rancimat and PDSC measurements, respectively (Table 3). Herein, $E_{\mathrm{a}}$ values obtained using Rancimat test were lower than that using the isothermal PDSC technique, which is in agreement with Ciemniewska-Żytkiewicz et al. [35]. Moreover, Ostrowska-Ligęza et al. [38] studied oil extracted from corn grains and used a dynamic PDSC, which resulted in oxidation $E_{\mathrm{a}}$ of $46.3 \mathrm{~kJ} \mathrm{~mol}^{-1}$.

In terms of oils, the $E_{\mathrm{a}}$ value is affected by the degree of unsaturation $[39,40]$. It was previously reported that a high PUFA content would lower, while high MUFA and SFA content would increase the $E_{\mathrm{a}}$ value for lipid oxidation process [40]. It stays in agreement with results obtained herein, when compared with oils containing smaller PUFA content: hazelnut oil (Rancimat $E_{\mathrm{a}}=84.7 \mathrm{~kJ} \mathrm{~mol}^{-1}$; PDSC $E_{\mathrm{a}}=89.1 \mathrm{~kJ} \mathrm{~mol}^{-1}$ ) and rapeseed oil (Rancimat $E_{\mathrm{a}}=80.99 \mathrm{~kJ} \mathrm{~mol}^{-1}$; PDSC $E_{\mathrm{a}}=92.69 \mathrm{~kJ} \mathrm{~mol}^{-1}$ ) [35].

Taking into consideration the rates of lipid oxidation (Table 3) as a function of temperature, the higher the process temperature, the higher the oxidation rate [40]. The $\mathrm{k}$ values for camelina oils demonstrated the same pattern and were 18-22 times higher, respectively, at 130 than at $90{ }^{\circ} \mathrm{C}$.

According to our knowledge, this paper is the first attempt to determine thermokinetic oxidation parameters of camelina oils and to study oxidation stability of this oil in various temperatures using pressure differential scanning calorimetry (PDSC). Therefore, it is impossible to compare directly our results with results obtained by other researchers.

\section{Conclusions}

The preliminary results of the oxidative stability of camelina oil using Rancimat test and isothermal PDSC technique presented herein showed a strong relationship between the values of both analytical methods usedRancimat $\tau_{\text {on }}$ and PDSC $\tau_{\max }$. Thus, PDSC can be recommended as an appropriate objective method for assessing the oxidative stability of camelina oils. Due to the high equipment costs and the use of pure oxygen as the carrier gas, PDSC method has not been commercially popularized yet to evaluate oxidative stability of oils. However, the inestimable advantages of PDSC, like shorter test time, small size of sample and no reagents needed, are still valuable. Because of that PDSC has a potential to be successfully applied as an alternative method for oxidative stability assessment of cold-pressed oils, including camelina oil.

Open Access This article is distributed under the terms of the Creative Commons Attribution 4.0 International License (http://crea tivecommons.org/licenses/by/4.0/), which permits unrestricted use, distribution, and reproduction in any medium, provided you give appropriate credit to the original author(s) and the source, provide a link to the Creative Commons license, and indicate if changes were made.

\section{References}

1. Abramovic H, Abram V. Physico-chemical properties, composition and oxidative stability of camelina sativa oil. Food Technol Biotechnol. 2005;43:63-70.

2. Imbrea F, Jurcoane S, Hălmăjan HV, Duda M, Botoş L. Camelina Sativa: a new source of vegetal oils. Rom Biotechnol Lett. 2011;16(3):6263-70.

3. Hrastar R, Abramovič H, Košir IJ. In situ quality evaluation of Camelina sativa landrace. Eur J Lipid Sci Technol. 2012;114(3):343-51.

4. Ghamkhar K, Croser J, Aryamanesh N, Campbell M, Kon'kova N, Francis C. Camelina (Camelina sativa (L.) Crantz) as an alternative oilseed: molecular and ecogeographic analyses. Genome. 2010;53(7):558-67.

5. Abramovic H, Butinar B, Nikolic V. Changes occurring in phenolic content and oxidative stability of Camelina sativa oil during storage. Food Chem. 2007;104:903-9.

6. Codex Alimentarius, FAO/WHO Codex standard for named vegetable oil. Codex Alimentarius. Amendment 2005; 2011.

7. Wroniak M, Ptaszek A, Ratusz K. Assessing the effect of pressing conditions in expeller press on quality and chemical composition of rapeseed oil. Zywn-Nauk Technol Jakosc. 2013;20:92-104.

8. Minkowski K, Grzeskiewicz S, Jerzewska M. Ocena wartości odżywczej olejów roślinnych o dużej zawartości kwasów linolenowych na podstawie składu kwasów tłuszczowych, tokoferoli i steroli. Zywn-Nauk Technol Jakosc. 2011;75:124-35.

9. Raczyk M, Popis E, Kruszewski B, Ratusz K, Rudzińska M. Physicochemical quality and oxidative stability of linseed (Linum usitatissimum) and camelina (Camelina sativa) cold-pressed oils from retail outlets. Eur J Lipid Sci Technol. 2015. doi:10.1002/ ejlt.201500064.

10. Szterk A, Roszko M, Sosińska E, Derewiaka D, Lewicki PP. Chemical composition and oxidative stability of selected plant oils. J Am Oil Chem Soc. 2010;87(6):637-45.

11. Eidhin DN, Burke J, O'Beirne D. Oxidative stability of omega-3 rich camelina oil and camelina oil-based spread compared with plant and fish oils and sunflower spread. J Food Sci. 2003;68:345-53.

12. Abramovic H, Butinar B, Nikolic V. Changes occurring in phenolic content, tocopherol composition and oxidative stability of Camelina sativa oil during storage. Food Chem. 2007;104:903-9.

13. Kasetaite S, Ostrauskaite J, Grazuleviciene V, Svediene J, Bridziuviene D. Camelina oil-and linseed oil-based polymers with bisphosphonate crosslinks. J Appl Polym Sci. 2014;131(17):40683.

14. Zaleckas E, Makarevičienè V, Sendžikienė E. Possibilities of using Camelina sativa oil for producing biodiesel fuel. Transport. 2012;27(1):60-6.

15. Soriano NU, Narami A. Evaluation of biodiesel derived from Camelina sativa oil. J Am Oil Chem Soc. 2012;89:917-23. doi:10.1007/s11746-011-1970-1. 
16. Farhoosh R, Niazmand R, Rezaei M, Sarabi M. Kinetic parameter determination of vegetable oil oxidation under Rancimat test conditions. Eur J Lipid Sci Technol. 2008;110:587-92.

17. Kowalski B, Ratusz K, Kowalska D, Bekas W. Determination of the oxidative stability of vegetable oils by differential scanning calorimetry and rancimat methods. Eur J Lipid Sci Technol. 2004;106:165-9.

18. Tan CP, Man YC, Selamat J, Yusoff MSA. Application of Arrhenius kinetics to evaluate oxidative stability in vegetable oils by isothermal differential scanning calorimetry. J Am Oil Chem Soc. $2001 ; 78(11): 1133-8$.

19. Litwinienko G. Analysis of lipid oxidation by differential scanning calorimetry. In: Analysis of lipid oxidation. Champaign: JAOCS Press; 2005. p. 152-193.

20. Ostrowska-Ligeza E, Bekas W, Kowalska D, Lobacz M, Wroniak M, Kowalski B. Kinetics of commercial olive oil oxidation: dynamic differential scanning calorimetry and Rancimat studies. Eur J Lipid Sci Technol. 2010;112(2):268-74.

21. Kowalska D, Kostecka M, Tarnowska K, Kowalski B. Oxidative stabilities of enzymatically interesterified goose fat and rapeseed oil blend by rancimat and PDSC. J Therm Anal Calorim. 2014;115(3):2063-70.

22. ISO 3960:2012. Animal and vegetable fats and oils-determination of peroxide value-iodometric (visual) endpoint determination. International Organization for Standardization, Geneva, Switzerland.

23. ISO 660:2009. Animal and vegetable fats and oils-determination of acid value and acidity. International Organization for Standardization, Geneva, Switzerland.

24. ISO 6885:2012. Animal and vegetable fats and oils: determination of anisidine value. International Organization for Standardization, Geneva, Switzerland.

25. AOCS Official Method Ce 1 h-05 2005. Determination of cis-, trans-, saturated, monounsaturated and polyunsaturated fatty acids in vegetable or non-ruminant animal oils and fats by capillary GLC.

26. AOCS Official Method Ce 2-66. Preparations of methyl esters of fatty acids; 1997.

27. ISO 6886:2009. Animal and vegetable fats and oils - determination of oxidation stability (accelerated oxidation test). International Organization for Standardization, Geneva, Switzerland.

28. Sokal RR., Rohlf FJ. Biometry. The principles and practice of statistics in biological research. 4th ed. New York: Freeman and Co.; 2005.
29. Zubr J, Matthaus B. Effect of growth conditions on fatty acids and tocopherols in Camelina sativa oil. Ind Crops Prod. 2002;15:155-62.

30. Minkowski K, Grzeskiewicz S, Jerzewska M, Ropelewska M. Chemical composition profile of plant oils with high content of linolenic acids. Zywn-Nauk Technol Jakosc. 2010;17(6):146-57.

31. Popis E, Ratusz K, Krygier K. Quality assessment of selected refined and cold-pressed rapeseed oils available on Polish market. Aparatura Badawcza i Dydaktyka. 2014;19(3):251-8.

32. Zaanoun I, Gharby S, Bakass I, Ait-addi E, Ait-ichou I. Kinetic parameter determination of roasted and unroasted argan oil oxidation under Rancimat test conditions. Grassas y accites. 2014;17(6):e033.

33. Abramovič H, Abram V. Effect of added rosemary extract on oxidative stability of Camelina sativa oil. Acta Agric Slov. 2006;87(2):255-61.

34. Ratusz K, Kowalski B, Gruczynska E, Tarnowska K, Bekas W, Kowalska M. Evaluation of antioxidants activity in vegetable oils and triacylglycerol matrices by Rancimat measurements. Riv Ital Sost Grasse. 2002;79:251-5.

35. Ciemniewska-Żytkiewicz H, Ratusz K, Bryś J, Reder M, Koczoń P. Determination of the oxidative stability of hazelnut oils by PDSC and Rancimat methods. J Therm Anal Calorim. 2014;118(2):875-81.

36. Kowalski B. Thermoanalytical analysis of vegetable oil oxidation as an autocatalytic reaction. Pol J Food Nutr Sci. 1992;1(42):51-60.

37. Kowalski B. Thermokinetic analysis of edible oils and fats oxidation. Warsaw University of Life Sciences Press; 1994.

38. Ostrowska-Ligeza E, Wirkowska M, Kowalski B. Thermo-kinetic analysis of corn grain fat using differential scanning calorimetry. Zywn-Nauk Technol Jakosc. 2009;16(1):128-39.

39. Kodali DR. Oxidative stability measurement of high stability oils by pressure differential scanning calorimeter (PDSC). J Agric Food Chem. 2005;53:7649-53.

40. Adhvaryu A, Erhan SZ, Liu ZS, Perez JM. Oxidation kinetic studies of oils derived from unmodified and genetically modified vegetables using pressurized differential scanning calorimetry and nuclear magnetic resonance spectroscopy. Thermochim Acta. 2000;364:87-97. 